\title{
Congenital Cortical Hyperostosis
}

National Cancer Institute

\section{Source}

National Cancer Institute. Congenital Cortical Hyperostosis. NCI Thesaurus. Code C84645.

A rare cong enital disorder characterized by thickening or expansion of the bones. 